\title{
Spontaneous congenital non-pigmented epithelial cysts of the iris stroma
}

Institute of

Ophthalmology, London A D A Paridaens K Deuble

A C E McCartney

Correspondence to: Dr A C E McCartney, Department of Pathology, Institute of Ophthalmology, 17-25 Cayton Street, London ECIV 9AT.

Accepted for publication 30 May 1991

\begin{abstract}
Histopathological and immunohistochemical findings in 11 patients with spontaneous congenital non-pigmented epithelial cysts of the iris stroma were studied. The cysts were lined by stratified squamous to unilayered cuboidal non-pigmented epithelium. Goblet cells were present in nine cysts, indicating a similarity to conjunctival epithelium. The demonstration of higher-molecular-weight keratins and absence of S-100 protein, by monoclonal and polyclonal antibodies, argues for surface ectodermal rather than neuroectodermal origin of the cysts. Theories of embryogenesis have been conflicting, but our results support the theory that they arise from surface ectoderm, displaced probably at the time of lens vesicle formation. The finding of normally sited subepithelial S-100 positive melanocytes may suggest that ectopic conjunctival epithelium can induce normal patterns of migration of neural crest cells.
\end{abstract}

Spontaneous congenital non-pigmented epithelial cysts of the iris stroma are uncommon unilateral lesions, usually presenting in the first few months of life. They appear as thin walled vesicles on the anterior surface of the iris, projecting into the anterior chamber. Clinically and histologically it is very difficult to distinguish spontaneous stromal cysts from acquired (for example, post-traumatic) stromal cysts, but the latter usually give rise to more complications, such as secondary glaucoma, corneal oedema, and iridocyclitis. ${ }^{1}$

Whereas acquired stromal cysts are known to arise from implanted surface epithelium after penetrating ocular trauma or surgery, ${ }^{2}$ the aetiology of spontaneous stromal cysts has been a matter of longstanding controversy, and neuroectodermal, ${ }^{3-11}$ surface ectodermal, ${ }^{12-19}$ and mesodermal ${ }^{20-22}$ origins have been suggested in different reports.

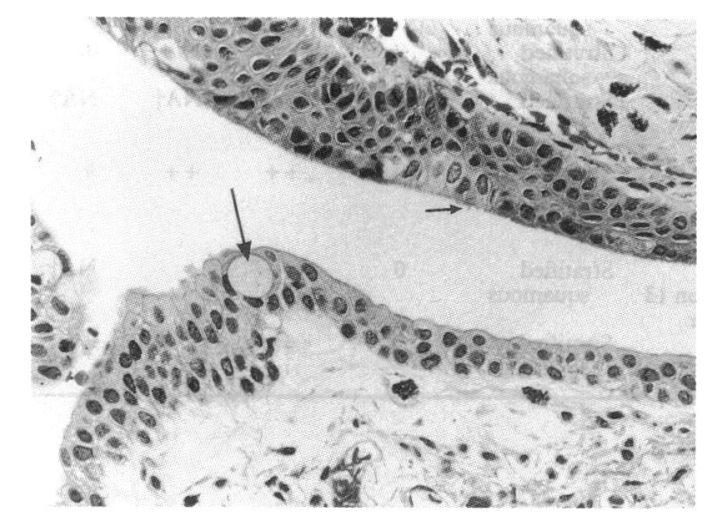

We examined the histopathological and immunohistochemical features of spontaneous non-pigmented epithelial cysts of the iris stroma in a series of 11 patients. On the basis of these observations we discuss the most plausible histopathogenetic theory for this iris lesion.

\section{Case report}

In September 1986 a girl aged 10 months, was seen at the Hospital for Sick Children, London. She had been born at term following a normal pregnancy and delivery. Her general health and development had also been normal. The family history was normal. When she was 2 months old her parents noticed a 'freckle' on the iris of the left eye. On examination a brownish, semitranslucent cystic lesion was seen in the iris stroma, replacing it and distorting the pupil. It was located inferiorly and involved the full iris thickness, bulging forward into the anterior chamber, and touching the corneal endothelium. Iris tissue behind the cyst was present but greatly thinned.

A CT scan and ultrasound examination showed no other abnormality. On 22 October 1986 the cyst was aspirated. Using healonid we stripped the cyst from the endothelium. Only partial removal and marsupialisation were possible, because the posterior leaf of the cyst formed the anterior leaf of the iris stroma.

This procedure failed to prevent recurrence, and shortly afterwards the cyst reformed. On 19 November 1986 a scleral and corneal flap was made inferiorly and a large sector iridectomy was carried out, with complete removal of the cyst. Postoperatively the eye settled well and no complications were seen.

The aspirate from the cyst showed clumps of epithelial cells and neutrophils. The iris cyst was lined by a layer of stratified cuboidal cells with prominent goblet cells, and very occasional oligocilia, on top of a layer of attenuated iris stroma (Fig 1).

\section{Materials and methods}

Pathological records, dating from 1952 through 1990 and kept in the Department of Pathology, Institute of Ophthalmology, were reviewed for patients with spontaneous congenital cysts of the iris stroma. Clinical notes, kept in Moorfield Eye Hospital, were analysed in addition to the pathology records. When the clinical notes were missing, the referring ophthalmologist was contacted for further information. For each patient we recorded as completely as possible the following data: date of birth, age at treatment, sex, laterality, history of trauma (including intrauterine trauma), associated ocular findings (decrease of visual acuity, inflammation, glau- 
coma, corneal oedema, cataract), referring diagnosis, clinical course, type of treatment, and complications. Patients with a documented history of (intrauterine) trauma or perforating injuries were excluded from this study.

Sections stained with haematoxylin and eosin and periodic acid Schiff were reviewed to verify the diagnosis of congenital cyst of the iris stroma. All selected specimens were subsequently stained with antibodies to S-100 antigen (DAKO) and cytokeratins (CAM 5.2 (mouse IgG2a, Becton and Dickinson) and wide spectrum screening rabbit polyclonal antikeratins (A575 and Z622, DAKO)) by means of a standard peroxidaseantiperoxidase technique, except when celloidin sections only were available.

The type of epithelium was recorded, as was the presence of goblet cells, keratinisation, hypoor hyperplasia of the iris stroma, the presence of a basal lamina, cataractous lens remnants, and the results of staining patterns with the panel of antibodies.

\section{Results}

Records of 13 patients with a diagnosis of iris stromal cyst were reviewed. Two patients were excluded from this study: one patient has a history of penetrating ocular trauma, while the other had an iris cyst originating from the iris pigment epithelium. In the selected group of patients eight were male and three were female. Eight patients had presented with an iris stromal cyst at birth or early childhood, while in three patients the cyst had become visible only in adulthood. In eight patients the right eye was involved, in three the left. No bilateral disease was noted. In 10 patients the referring diagnosis was congenital cyst of the iris (stroma), and one patient (Table 1 , no. 8) was referred with a diagnosis of buphthalmic eye with congenital abnormality.
In none of the selected patients was there a documented history of (intrauterine) trauma or surgery. In two patients there was marked inflammation of the iris cyst and the surrounding stroma. In one of these patients (no. 2), there was an intracystic collection of pus. In five patients there was raised intraocular pressure; two of them showed signs of glaucoma. In three patients 'endothelial touch' was noted. The clinical course varied. In some patients there had been a stable, small cyst for years, followed by rapid growth in several weeks, sometimes leading to such complications as impairment of visual acuity or corneal touch and oedema. In the majority there has been a gradually enlarging iris cyst, which had been noted at birth, while in other patients the cyst had had a rapid growth phase, immediately after birth.

In nine patients the initial treatment was excision of the cyst. In one patient an inflamed cyst was excised after intensive topical steroid treatment had failed, and another patient required enucleation because of buphthalmos and cataract. In two patients there was a recurrence after excision, and they were subsequently treated by sector iridectomy. A 13-year-old patient (no. 10), whose stromal cyst of the right iris had been excised successfully at the age of 4 months, underwent enucleation of his right eye, which had become buphthalmic. Histopathological examination of the enucleation specimen showed evidence of severe chronic angle closure glaucoma, limbal staphylomas, iris atrophy, and buphthalmos.

The results of histopathological and immunohistochemical examination of the 11 specimens are summarised in Table 1.

\section{Discussion}

Spontaneous non-pigmented epithelial cysts arising in the stroma of the iris are uncommon

Table 1 Histopathological and immunocytochemical findings in spontaneous non-pigmented epithelial cysts of the iris stroma

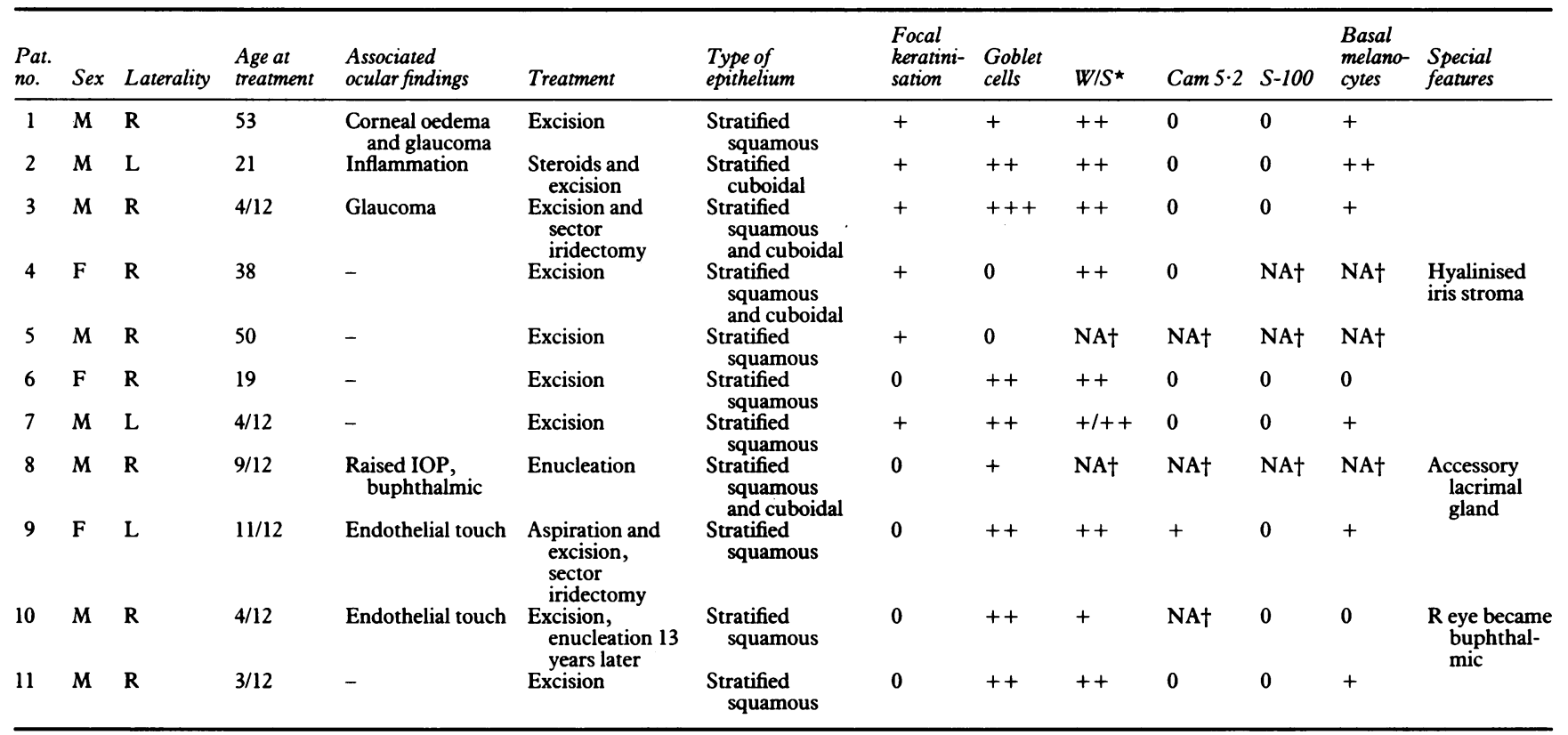




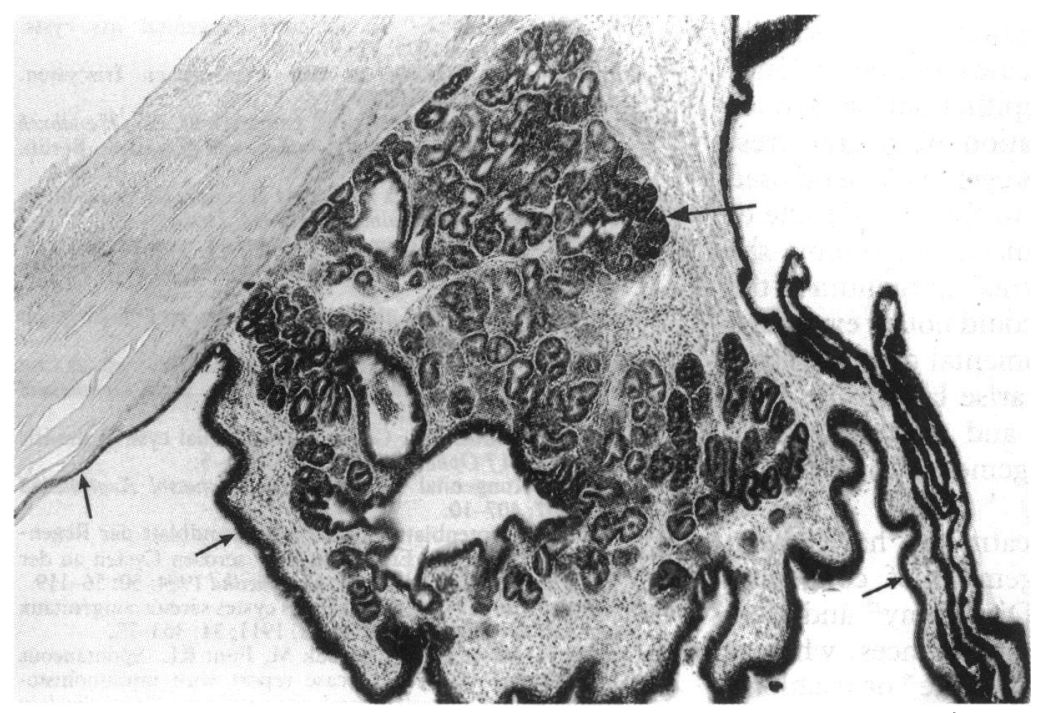

Figure 2 This enucleation specimen of a buphthalmic right eye shows ectopic lacrimal gland (large arrow) in iris stroma, adjacent to the epithelium (small arrows) of a large congenital stromal cyst, which fills the anterior chamber. (Haematoxylin and eosin, $\times 45$.

Figure 3 Antibodies to S-100 show melanocytes (arrows), neural crest derivatives, in close relation to the epithelium of the iris cyst. Dendritic melanocytes within the iris stroma are also $S-100$ positive. ( $S 100$, $\times 450$.

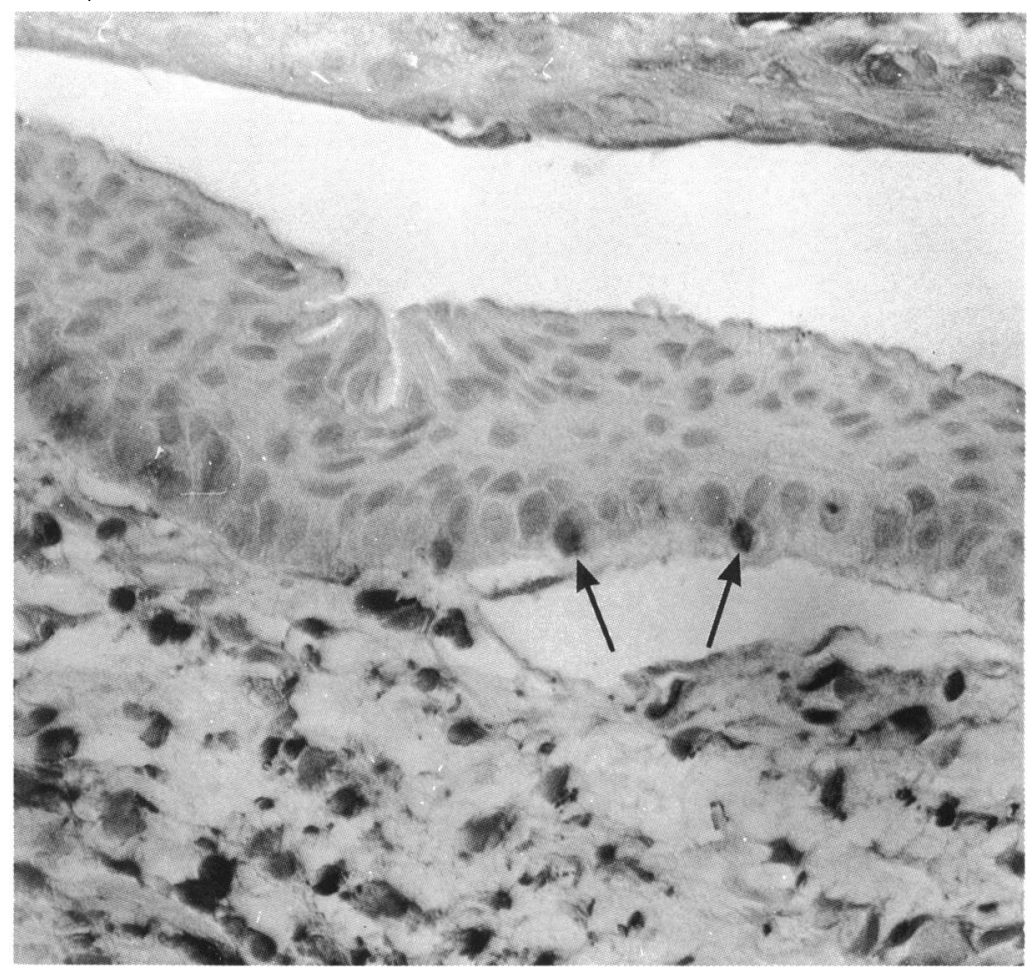

Most epithelial cells contain cytokeratins of varying subtypes, the expression of which depends on the type of epithelium, the degree of histological differentiation, and the state of the cell cycle. This range of expression allows limited subcategorisation of epithelia on the basis of cytokeratin profiles. ${ }^{23}$ Higher-molecularweight cytokeratins are typically found in complex, stratified epithelium such as that of skin, cervix, and oesophagus, while lower-molecularweight cytokeratins tend to be present in unilayered epithelia such as renal tubular epithelium, endometrium, glandular acinar cells, and neuroendocrine cells. ${ }^{23}$ Combinations of higherand lower-molecular-weight cytokeratins are seen in ductal epithelia such as breast epithelium and bronchial epithelium. ${ }^{23}$

Staining for CAM $5 \cdot 2$, which detects lowermolecular-weight cytokeratin subtypes, was negative in most cases examined, except in one, which showed a mildly positive reaction. Conversely, staining with wide-spectrum screening antikeratins (Z622 and A575, DAKO), one of which (A575) demonstrates higher-molecularweight cytokeratins, was positive in all cases. This finding is suggestive of more complex stratified epithelia, which tend to be of surface ectodermal origin.

None of the epithelial cells showed positive staining with the antibodies to S-100 antigen. However, staining with anti-S-100 was positive in the stromal dendritic melanocytes derived from neural crest. Although antibodies to $S-100$ are highly sensitive in detecting cells derived from neural crest such as melanocytes, their specificity is low, for they stain a variety of neural, neuroendocrine, mesenchymal, and epithelial tumours. ${ }^{23}$ The absence of S-100 antigen in the epithelia of all cases makes an origin from the neural crest unlikely.

The histopathological and immunohistochemical findings in our study suggest that in most cases spontaneous non-pigmented epithelial cysts of the iris stroma originate from surface ectoderm. Previous immunohistochemical studies showed positive reactions to epithelial cytokeratin markers but failed to differentiate between surface ectodermal and neuroectodermal origin. ${ }^{174}$ In the study by Grutzmacher et al. ${ }^{24}$ two cases were examined for antigens such as muscle specific actin, smooth muscle actin, vimentin, human melanoma antigen, and S-100 protein, but no positive reaction was seen.

In one case (no. 8) an accessory lacrimal gland was seen adjacent to the cyst (Fig 2). This abnormality has been reported before, ${ }^{25} 26$ and may in addition support the putative surface ectodermal origin of the cyst, as lacrimal gland is, like conjuctiva, a surface ectodermal derative.

Some authors who favour the theory that the cysts are derived from surface ectoderm have postulated that entrapment of ectopic tissue probably takes place at the time of formation of the lens vesicle, during the fourth week of embryogenesis. ${ }^{1+16}$

The S-100 antibodies showed subepithelial melanocytes, which were separated from the iris stroma by a clear basal lamina (Fig 3). Migration of neural crest cells, destined to become melanocytes, is known to occur much later in embryo- 
genesis than lens vesiculation. The normally sited melanocytes in most cases may be evidence that ectopic conjunctival epithelium can induce normal patterns of migration of neural crest cells. In our study some iris cysts were diagnosed and treated in the second to the fifth decade of life. In the absence of a history of trauma the presence of surface ectodermal epithelium in the iris stroma in our opinion could not be explained otherwise than by developmental displacement. Spontaneous cysts which arise late in life have probably been dormant and become visible owing to a sudden engorgement, triggered by some unknown factor.

Several forms of treatment have been advocated for the management of congenital cysts of the iris stroma. Diathermy ${ }^{27}$ and electrolysis $^{28}$ frequently cause recurrences, whereas aspiration with injection of iodine ${ }^{29}$ or trichloroacetic acid ${ }^{30}$ may give rise to harmful intraocular complications. In most of our patients the cysts were excised after a period of documented growth, in which the visual axis was compromised. In $20 \%$ of the patients the cyst recurred, and an additional sector iridectomy was carried out. The cyst wall should be totally removed if possible, which may require an iridocyclectomy if the ciliary body is involved.

Dr A D A Paridaens was supported by grants from the Stichting Bevordering van de Gezondheidszorg and Stichting de Drie Lichten, The Netherlands.

We thank Mr D Taylor, FRCS, for the illustrative case history and Mr R A Alexander, MPhil, for his help with the immunocytochemical staining.

1 Shields JA, Kline MW, Augsburger JJ. Primary iris cysts: a review of the literature and report of 62 cases. BrF Ophthalmol 1984; 68: 152-66.

2 Farmer SG, Kalina RE. Epithelial implantation cyst of the iris. Ophthalmology 1981; 88: 1286-9.

3 Rush JA, Weinstein GW, Meriwether WA. Spontaneous nonpigmented iris cyst. Arch Ophthalmol 1982;100:304-5.

4 Juselius E. Die spontanen Iriszysten, ihre Pathogenese und Entwicklung. Klin Monatsbl Augenheilkd 1908;46: 300.

5 Tertsch R. Die spontane Iriszyste. Arch Clin Exp Ophthalmol 1914; 88: 72 .
6 Roy RH, Hanna C. Spontaneous congenital iris cysts. Am $\mathcal{F}$ Ophthalmol 1971; 72: 97-108.

7 Bergemann $H$. Beitrag zu den angeborenen Iriscysten. Arch Augenheilkd 1910; 66: 37.

8 Ginsberg S. Uvea. In: Henke F, Lubarsch O, eds. Handbuch der speziellen pathologischen Anatomie und Histologie. Berlin: Springer, 1928; 1: 389-577.

9 Vrabec F. Contribution à l'étude de la genèse de cystes libres intra-oculaires. Ophthalmologica 1948; 116: 129-40.

10 Politzer G. Die Entstehung der spontanen epithelialen Iriscysten. Graefes Arch Clin Exp Ophthalmol 1953; 153: 497cysten.

11 Mann I. Developmental abnormalities of the eye. Philadelphia: Lippincott, 1957: 295-6.

12 Hvidberg-Hanson J, Larsen FE. Congenital iris cyst. A case study by light and electron microscopy. Acta Ophthalmol (Kbh) 1972;50: 501-14.

13 Klein BA, Tanner GS. Congenital epithelial cyst of the iris stroma. Am $\mathcal{F}$ Ophthalmol 1963; 55: 291-5.

14 Koch K. Kongenital Iriscyste. Klin Monatsbl Augenheilkd 1921; 67: 407-10.

15 Streiff JJ. Kryptenblatt und Kryptengrundblatt der Regenbogenhaut und die Entstehung der serosen Cysten an der vorderen Seite der Iris. Arch Augenheilkd 1904; 50: 56-119.

16 Nadal R. Note sûr la pathogénie des cystes séreux congénitaux de l'iris. Arch Ophthalmol (Paris) 1911; 31: 363-73.

17 Coburn A, Messmer EP, Boniuk M, Font RL. Spontaneous intrastromal iris cyst. A case report with immunohistochemical and ultrastructural observations. Ophthalmology 1985; 92: 1691-5.

18 Sugar HS, Nathan LE. Congenital epithelial cysts of the iris stroma. Ann Ophthalmol 1982; 14: 483-5.

19 Waeltermann JM, Hettinger ME, Cibis GW. Congenital cysts of the iris stroma. Am $\mathcal{F}$ Ophthalmol 1985; 100: 549-54.

20 Laval J. Spontaneous cyst of the iris. Am $\mathcal{f}$ Ophthalmol 1947 30: 55-7.

21 Guerry D, Wiesinger $H$. Spontaneous cyst of the iris stroma. Am $\mathcal{O}$ Ophthalmol 1957; 44: 106-7.

22 Witschel H, Berndt K, Mackenson G. Angeborene Stromazyste der Iris. Ein klinisch-histopathologischer Fallbericht. Klin Monatsbl Augenheilkd 1979; 174: 572.

23 Corwin DJ, Gown AM. Review of selected lineage-directed antibodies useful in routinely processed tissues. Arch Pathol Lab Med 1989; 113: 645-52.

24 Grutzmacher RD, Lindquist TD, Chittum ME, Bunt-Milam AH, Kalina RE. Congenital iris cysts. Br f Ophthalmol 1987; 71: 227-34.

25 Bruce G. Aberrant glandular tissue in iris. Trans Am Acad Ophthalmol 1952; 56: 47-51.

26 Hunter WS. Aberrant intraocular lacrimal gland tissue. Brf Ophthalmol 1960; 44: 619-25.

27 Vail D. Treatment of cysts of the iris with diathermy coagulation. Am $\mathcal{F}$ Ophthalmol 1954; 38: 513-8.

28 Kennedy AJ. Treatment of cysts of the iris with electrolysis. Arch Ophthalmol 1956; 55: 522-5.

29 Alger EM. Large implantation cyst of the iris treated by aspiration and injection of iodine. Arch Ophthalmol 1932; 7 : aspiration.

30 Swan KC. Epithelial cell cysts of the anterior chamber treated by acid injections. Doc Ophthalmol Proc Ser 1979; 18: 362-70. 